\title{
Serum prolactin and cortisol concentrations after grand mal seizures
}

\author{
R J ABBOTT, M C K BROWNING, AND D L W DAVIDSON
}

From the Department of Neurology, Dundee Royal Infirmary, and the Department of Biochemical Medicine, Ninewells Hospital, Dundee

SUMMARY Serial serum prolactin and cortisol levels were measured in five patients after a grand mal seizure and in four volunteers with simulated seizures. Single levels were measured after a witnessed seizure in 26 patients and in a matched control group. Significant increase in both prolactin and cortisol levels occurred after seizures. The change in cortisol level may reflect a nonspecific stress response, but the increase in prolactin levels could not be accounted for on this basis, and probably indicates an alteration in hypothalamic neurotransmitter activity during the seizure. These findings may have clinical value in the diagnosis of epilepsy.

Prolactin release from the anterior pituitary gland is thought to be controlled by release of neurotransmitter from the hypothalamus. Inhibition by dopamine ${ }^{1}$ is important but noradrenaline ${ }^{2}$ and gamma aminobutyric acid $(\text { GABA })^{3}$ may also inhibit prolactin release. The nature of the prolactin-releasing factor in mammals is uncertain, and the effect of 5-hydroxytryptamine $(5-\mathrm{HT})$ on prolactin release in man is still unclear. ${ }^{4-6}$.

Serum prolactin may, therefore, be considered as a peripheral marker of hypothalamic neurotransmitter activity. Many other factors are known to influence prolactin secretion, including stress $^{7}$ and drugs. ${ }^{8}$ Eleciroconvulsive therapy has been shown to produce a marked rise in serum prolactin," and in a recent uncontrolled study a significant increase in prolactin levels was found 20 minutes after a grand mal convulsion. ${ }^{10}$ Paroxysmal discharges occur during grand mal seizures in major ascending and descending pathways concerned with consciousness and motor control, but involvement of the hypothalamus has not been studied. If a clearly defined rise in serum prolactin occurs after seizures this might have clinical applications in the assessment of patients with episodes of loss of consciousness of uncertain aetiology. As stress

Address for reprint requests: Dr D L W Davidson, Department of Neurology, Dundee Royal Infirmary, Barrack Road, Dundee DD1 9ND.

Accepted 2 July 1979 increases serum cortisol to a greater extent than serum prolactin, ${ }^{\circ}$ both cortisol and prolactin were measured simultaneously as a guide to the stress factor involved, and to determine the pattern of hypothalamic-pituitary activity during a seizure.

\section{Method}

Plasma cortisol was measured by a widely used radio-immunoassay technique, ${ }^{11}$ and prolactin was also measured by radioimmunoassay using rabbit anti-human prolactin and ${ }^{125}$ I-labelled prolactin obtained from Eurohope Services Ltd, measured against the first international Reference Preparation for Prolactin (75/504) from the National Institute of Biological Standards and Controls, London.

Three groups of patients were studied.

1 Serial samples after grand mal seizures In five patients serial prolactin and cortisol levels were measured after a witnessed grand mal convulsion. Samples were taken at the times shown in the table.

2 Serial samples after simulated seizures Prolactin and cortisol levels were measured in four young healthy male volunteers immediately before, then 15 and 45 minutes after the voluntary simulation of tonic and clonic seizures for one minute.

3 Single estimations in post-ictal patients Twenty-six patients (16 male, 10 female) 
Table Serial prolactin and cortisol concentrations in five patients after a grand mal seizure

\begin{tabular}{|c|c|c|c|c|c|c|c|c|c|}
\hline Number & $\begin{array}{l}\text { Age } \\
(y r)\end{array}$ & Sex & & $0-15 \mathrm{~min}$ & $15-30 \mathrm{~min}$ & $30-60 \mathrm{~min}$ & $60 \longrightarrow 90 \mathrm{~min}$ & $90-120 \mathrm{~min}$ & $>120 \mathrm{~min}$ \\
\hline 1 & 22 & $\mathbf{M}$ & $\begin{array}{l}\text { Prolactin } \\
\text { Cortisol }\end{array}$ & 1528 & & 367 & & 339 & 410 \\
\hline 2 & 25 & $\mathbf{M}$ & $\begin{array}{l}\text { Prolactin } \\
\text { Cortisol }\end{array}$ & $\begin{array}{l}2870 \\
24.6\end{array}$ & $\begin{array}{l}2870 \\
24.8\end{array}$ & $\begin{array}{l}1646 \\
21.5\end{array}$ & $\begin{array}{r}760 \\
13.6\end{array}$ & $\begin{array}{r}603 \\
17.0\end{array}$ & $\begin{array}{r}382 \\
10.5\end{array}$ \\
\hline 3 & 19 & $\mathbf{M}$ & $\begin{array}{l}\text { Prolactin } \\
\text { Cortisol }\end{array}$ & & $\begin{array}{l}1195 \\
23.7\end{array}$ & $\begin{array}{r}868 \\
32.9\end{array}$ & $\begin{array}{r}597 \\
20.1\end{array}$ & & \\
\hline 4 & 22 & $\mathbf{M}$ & $\begin{array}{l}\text { Prolactin } \\
\text { Cortisol }\end{array}$ & $\begin{array}{r}938 \\
10.6\end{array}$ & & $\begin{array}{l}1115 \\
11.8\end{array}$ & & $\begin{array}{l}895 \\
12.4\end{array}$ & \\
\hline 5 & 78 & $\mathbf{F}$ & $\begin{array}{l}\text { Prolactin } \\
\text { Cortisol }\end{array}$ & & $\begin{array}{r}499 \\
46.0\end{array}$ & $\begin{array}{r}394 \\
40.0\end{array}$ & $\begin{array}{r}349 \\
38.0\end{array}$ & $\begin{array}{r}305 \\
43.0\end{array}$ & $\begin{array}{r}296 \\
39.2\end{array}$ \\
\hline
\end{tabular}

Serum prolactin $=\mathrm{mU} / \mathrm{L}$

Serum cortisol $=\mu \mathrm{g} / \mathrm{dl}$

with known epilepsy, and on a variety of anticonvulsant drugs, had blood samples taken in an accident department within two hours of a witnessed grand mal seizure. The exact times of the ictus could not always be determined, but in the majority the samples were taken between 30 and 60 minutes and none greater than 120 minutes. All studies were done between 0900 and 1800 . This limited time excludes the greatest changes in diurnal rhythm of cortisol, and the increase of prolactin during sleep. Although there may be short-term or "pulsed" releases of prolactin during the day, these are variable and cannot be predicted. Therefore the times of sampling within the 0900-1800 studies were not controlled. Samples were also obtained from an age-matched and sexmatched control group seen in the same department. All presented with acute illness which could not be confused with epilepsy, and none were receiving medication. The degree to which these patients were stressed was difficult to assess clinically, but an attempt was made to select patients who were severely ill.

Results were analysed statistically using Student's $t$ test.

\section{Results}

Serial estimations of prolactin after a seizure showed initial high serum levels with a subsequent fall in three out of five patients (table). The sequential changes in prolactin and cortisol in case 2 are shown in fig 1 comparing the serial levels to the two-hour concentration in each case. Case 4 had an unusually prolonged seizure lasting for 30 minutes and received diazepam, $10 \mathrm{mg}$ intravenously. Case 5 was an elderly wom $\mathrm{n}$, the other four patients were young men.

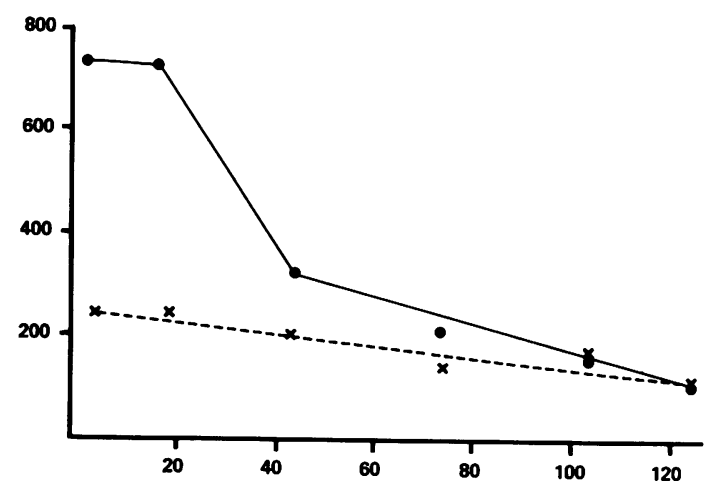

Fig 1 Serum prolactin (-) and cortisol (- - - ) concentrations after a seizure in patient 2 (concentrations are plotted as percentage of two-hour level).

Figure 2 shows the prolactin and cortisol levels after simulated seizures with a significant increase in cortisol at 15 minutes $(p<0.05)$ but no significant change in prolactin. We recognise that the intensity of muscular contraction and degree of

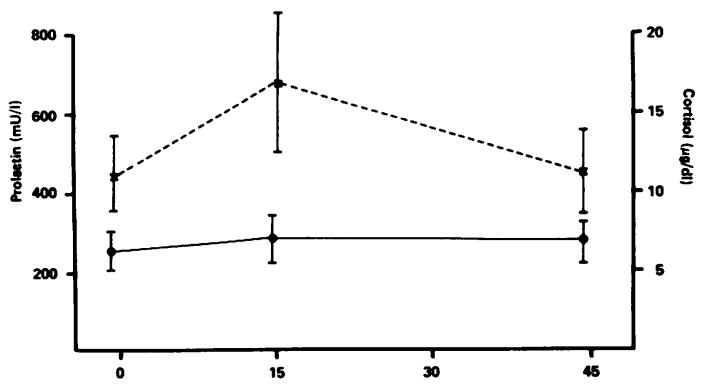

Fig 2 Serial cortisol (- - -) and prolactin (-) concentrations after simulated seizure in four subjects. 
stress are much less than occur in true grand mal seizures.

Prolactin levels in the postictal patients $(1195 \pm 1063 \mathrm{mU} / 1)$ were significantly higher than in control subjects $(496 \pm 350 \mathrm{mU} / 1)(\mathrm{p}<0.0025)$. Cortisol levels were also higher in the postictal group (postical 30.5 $\pm 10.5 \mu \mathrm{g} / \mathrm{dl} /(\mathrm{n}=10)$, control subjects $17.7 \pm 8.3 \mu \mathrm{g} / \mathrm{dl} /(\mathrm{n}=23)(\mathrm{p}<0.001)$. There was no significant age difference between the two groups-(postictal $37 \cdot 0 \pm 19 \cdot 3$, control subjects $37 \cdot 6 \pm 16 \cdot 2$ ) (fig 3 ).

When a subgroup of control subjects with cortisol levels greater than $20 \mu \mathrm{g} / \mathrm{dl}$ was considered there was no significant difference in cortisol levels (postictal 30.5 $\pm 10 \cdot 5 \mu \mathrm{g} / \mathrm{dl}(\mathrm{n}=10)$, control subjects $26 \cdot 1 \pm 3 \cdot 4 \mu \mathrm{g} / \mathrm{dl}(\mathrm{n}=10)$. However prolactin levels were still significantly higher in the postictal group (postictal subjects $1541 \pm$ $1582 \mathrm{mU} / 1$, control subjects $413 \pm 255 \mathrm{mU} / 1$ $(\mathrm{p}<0 \cdot 025)$.

\section{Discussion}

These results confirm the findings of Trimble ${ }^{10}$ that serum prolactin is increased after grand mal seizures. We have found the levels to be lower, but the time course of prolactin change to be similar to those reported after electroconvulsive therapy $(\mathrm{ECT})^{9}$. The prolactin may be very high five minutes after the ictus (case 2) but more detailed studies are required to establish the sequence of changes immediately after seizures.

Previous studies with ECT or epilepsy have not considered the non-specific effects of stress and cortisol levels have not been measured. The significantly higher cortisol levels in postictal patients than in control subjects may reflect the ill-defined hypothalamic response to a variety of threats which is broadly termed "stress", or it may arise as a primary effect upon the hypothalamus of the seizure itself. In a attempt to eliminate the stress factor we have selected a subgroup of apparently highly stressed control subjects indicated by high cortisol levels $(>20 \mu \mathrm{g} /$ $1 \mathrm{dl}$ ). In this group the cortisol concentrations, although still lower, were not significantly different from the postictal patients. The prolactin concentrations were significantly higher after a seizure than in this group of controls. A difference in cortisol and prolactin responses is also shown in the serial studies after a seizure-for example, in case 2 the prolactin was increased by $750 \%$ whereas the cortisol was increased by $230 \%$ at five minutes compared to the two-hour level. In simulated seizures, where only stress occurs, serum cortisol levels increased while prolactin
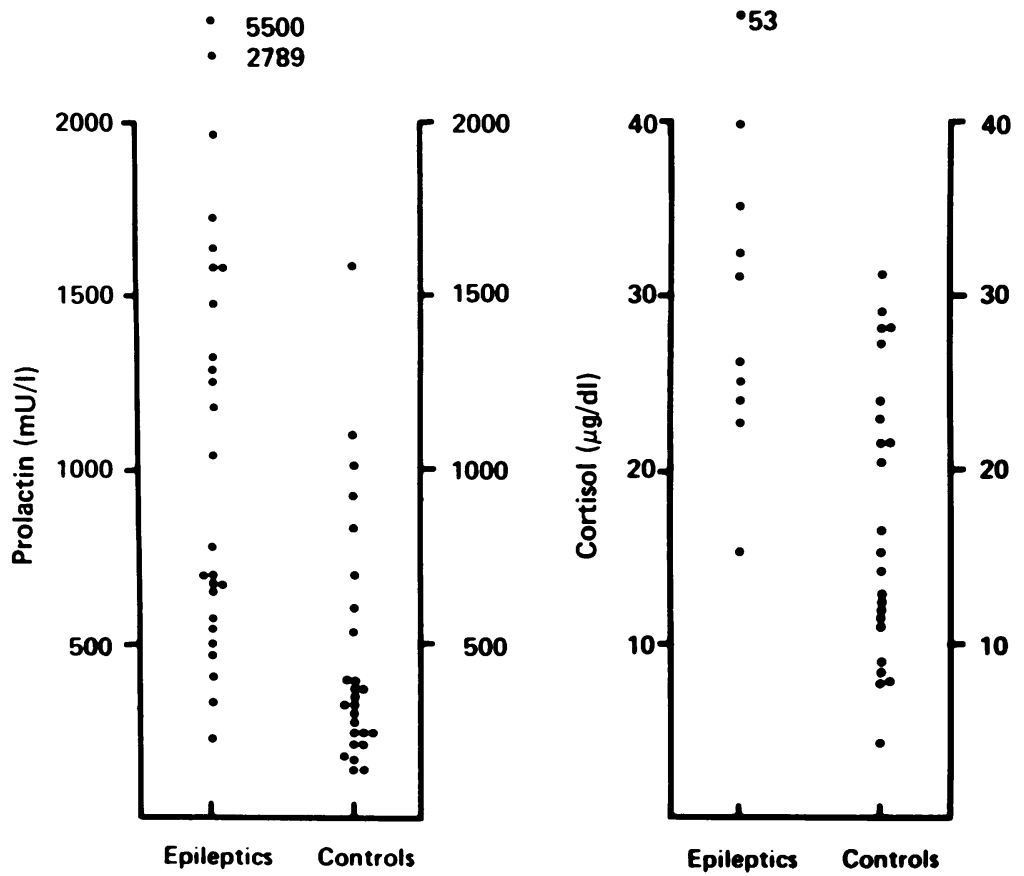

Fig 3 Serum prolactin (-) and cortisol (---) concentrations in post-ictal patients and control subjects. 
concentrations were unchanged. These findings are in keeping with the interpretation that serum prolactin elevation after a seizure results specifically from neuronal dysfunction associated with the seizure, rather than as a non-specific response to stress.

The mechanisms of the changes in hypothalamic-pituitary activity after seizures are still speculative, but the observations are important as they suggest that a specific pattern of hypothalamic neurotransmitter activity may occur during seizures-such as increase in 5-HT and inhibition of dopaminergic activity. The administration of 5-hydroxytryptophan (5-HTP), a precursor of 5-HT, to healthy volunteers has recently been shown to raise serum cortisol levels but not prolactin ${ }^{\theta}$ although other groups have demonstrated elevation in prolactin levels after 5-HTP. If this cortisol response is a direct effect of increased 5-HT activity at hypothalamic level it appears that 5-HT stimulates release of cortisol more readily than prolactin. Therefore, although the cortisol response after seizures may be mediated by $5-\mathrm{HT}$, other mechanisms are likely to be responsible for the prolactin release. In view of the established importance of tonic dopaminergic control of prolactin release one explanation is that inhibition of tuberoinfundibular dopamine release occurs in grand mal seizures. Other possible neurotransmitter mechanisms may involve noradrenaline ${ }^{2}$ and $\mathrm{GABA}^{3}$ although their effects on inhibition of prolactin release in man is unclear.

A simple biochemical marker of a recent seizure would be extremely valuable in the assessment of clinical problems, for example, in the differential diagnosis of hysteria, as discussed by Trimble ${ }^{10}$. Whether it may prove useful in distinguishing epilepsy from blackouts of other aetiology such as vasovagal attacks or transient cerebral ischaemia is uncertain, for studies of prolactin levels have not been done after cerebral ischaemia. Our results show a clear change in serum prolactin levels in three out of five patients followed serially after a seizure. Cases 4 and 5 did not show the same response. In case 4 the seizure was atypical with continuous minor clonic twitchings and coma for $\mathbf{3 0}$ minutes before termination with diazcpam, $10 \mathrm{mg}$ intravenously. The prolactin response may have occurred at the onset of the attack, or been modified by the type of seizure. It may also have been modified by diazepam therapy, although diazepam does not alter basal prolactin levels ${ }^{12}$ nor the response to metoclopramide. ${ }^{13}$ Case 5 was an elderly woman whose hypothalamic function may have differed from the younger male patients.

We have shown that in a population of postictal patients the serum prolactin level is significantly higher than after medical emergencies of other types. The postictal group included some patients with prolactin levels within the normal range, possibly because the initial rise was missed in those patients seen up to two hours after the ictus. Therefore, a normal serum prolactin level cannot be taken to exclude a seizure within two hours but a high level does strongly suggest this possibility. Further studies are required to determine whether a prolactin level taken within 30 minutes of the event allows a clearer distinction between epilepsy and non-paroxysmal disorders, including cerebral ischaemia.

Finally, these observations have been restricted to grand mal attacks, but further studies are required to determine whether the postulated alteration in hypothalamic neurotransmitters also occurs in other types of seizure, such as temporal lobe epilepsy and petit mal.

We thank Miss $\mathrm{S}$ Love for secretarial assistance, and $\mathrm{Dr} P$ De Vane, Dr AO House, and Dr IT Ferguson for their help in compiling the data.

\section{References}

1 Kamberi IA, Mical RS, Porter JC. Effects of anterior pituitary perfusion and intraventricular injection of catecholamines on prolactin release. Entocrinology 1971, 88:1012-20.

2 Schaar CJ, Clemens JA. The role of catecholamines in the release of anterior pituitary prolactin in vitro. Endocrinology 1974; 95: 1202-12.

3 Schally AV, Redding TW, Arimura A, Dupont $\mathrm{A}$, Linthicum JL. Isolation of gamma-amino butyric acid from pig hypothalamus and demonstration of its prolactin-release inhibiting (PIF) activity in vivo and in vitro. Endocrinology 1977; 100:681-91.

4 Kato Y, Nakai Y, Imura H, Chitiara K, Ohgo S. Effects of 5-hydroxytryptophan (5-HTP) on plasma prolactin levels in man. Clin Entocrinol Metab 1974; 38:695-7.

5 Beck-Peccoz P, Ferrari C, Rondena M. Failure of oral 5-hydroxytryptophan administration to affect prolactin secretion in man. Horm Res 1976; 7:303-7.

6 Browning MCK, Newton RW, Abbott RJ, Robertson AJ, Swanson Beck J. A comparison of the effects of stress on serum prolactin and cortisol levels. In preparation. 1979.

7 Neill JD. Effects of stress on serum prolactin and luteinising hormone levels during the estrous cycle of the rat. Endocrinology 1970; 87: 1192-7. 
8 Thorner MD Besser GM. Clinical significance of dopaminergic mechanisms in the hypothalamus and pituitary. In: O'Riorden $O$, ed. Recent Advances in Endocrinology and Metabolism. Edinburgh: Churchill Livingstone, 1978: 6.

9 Ohman R, Walinder J, Balldin J, Wallin L. Prolactin response to electroconvulsive therapy. Lancet 1976; 2:936-7.

10 Trimble RM. Serum prolactin in epilepsy and hysteria. Br Med J 1978; 2:1682.
11 Fahmy D, Read GF, Hillier SG. Some observations on the determination of cortisol in human plasma by radioimmunoassay using antisera against cortisol 3BSA. Steroids 1975; 26:267-80.

12 Noel GL, Suh HK, Stone JG. Human prolactin and growth hormone release during surgery and other conditions of stress. Clin Endocrinol Metab 1972; 35:840-51.

13 Wilson JD, King DJ, Sheridan B. Tranquillisers and plasma prolactin. Br Med J 1979; 1:123-4. 